\title{
How the Social Value Act (2012) Contributes to Wealth Inequality in the UK Construction Industry
}

\section{Greg Watts ${ }^{1}$ and Anthony Higham ${ }^{1}$}

${ }^{1}$ School of Science, Engineering and Environment, University of Salford, UK

Keywords: Construction, Social Value, Local Authority, Legislation.

\begin{abstract}
:
The Social Value Act (2012) (SVA) has legitimised public clients' use of socially responsible procurement criteria in construction and is used by some Local Authorities (LA's) with the ultimate aim of reducing inequality. Despite this, reports suggest inequality is increasing year on year. It could therefore be argued that the SVA is, at best, making no positive difference to inequality. At worst it is further amplifying the gap between rich and poor. LA's are also being forced to depend less on central Government funding, spending only the money they generate. It could therefore be argued LA's in socially disadvantaged areas will never generate the financial capital to invest in construction works. Therefore, never experience social value, unlike more affluent $L A$ 's, further exacerbating inequality. This paper aims to explore social value (SV) in more detail, analysing the changes in LA behaviour due to the SVA and funding cuts. The paper also explores if there is a link between increased SVA use and inequality. Interviews were conducted with LA's and construction contractors with the results revealing that in some instances the SVA serves to widen and reinforce inequality. Therefore, some LA's are potentially at risk of becoming trapped in a cycle of low income, low construction investment, and low levels of SV, resulting in low income and high deprivation. This research contributes to the previously unexplored negative ramifications of the SVA and what this means for contractor Corporate Social Responsibility practices.
\end{abstract}

\section{INTRODUCTION}

The United Kingdom (UK) construction industry has an annual value of over $£ 99 \mathrm{bn}$, accounts for $9 \%$ of the UK economic output and is responsible for creating over 2 million jobs (Rhodes, 2019). Despite such significant economic benefits, society remains highly critical of the industry on account of its widely publicised negative impacts on society and the environment (Barthorpe, 2010). Consequently, the many positives to the industry are often 
overlooked and taken for granted such as the responsible behaviour of organisations and the infrastructure and buildings we depend on every day. Attempts to change the negative societal opinions of the construction industry has resulted in construction organisations embracing Corporate Social Responsibility (CSR). CSR can be described as organisations adopting practices to protect and improve the environment and society as part of their business activities (Carroll, 2015). Whilst organisations embrace CSR for a variety of reasons it is arguably the public sector that pushes the CSR agenda forward.

The public sector itself accounts for approximately $26 \%$ of the construction industry and in addition to procuring goods and services for public use, public sector organisations such as Local Authorities (LAs) are now also able to maximise expenditure for additional societal benefit with the use of The Public Services (Social Value) Act (2012) (SVA). Using the SVA when awarding construction contracts allows LAs to consider the wider value contractors offer, and not just the lowest cost (Watson et al., 2016). The SVA helps LAs maximise the societal benefits they experience in times of austerity. Whilst the focus of the SVA and contractor CSR are not directly aimed at wealth inequality, if such concepts are delivered successfully it could be presumed that wealth inequity would reduce. However, despite the increasing use of the SVA, wealth inequality in the UK is increasing. This area is currently unexplored and so the aim of this deductive research is to analyse this emerging area in more detail. By conducting interviews with both contractors and LA's, and utilising the theoretical lens of legitimacy theory, this paper seeks to understand the impact of the SVA and funding cuts on LA's, the ramifications for construction contractors and their CSR practices, and the impact such legislation and practices have upon the levels of wealth inequality in society.

\section{THE CHANGING LANDSCAPE FOR LOCAL AUTHORITIES}

LAs are a substantial public sector client for the construction industry. However, the funding of LA's is directly influenced by government rules and regulations. During the previous decade the government have engaged in a process of austerity. This can be defined as a shared feeling of hardship and reduced expectations, or perhaps more optimistically as a shared feeling of hope that such joint suffering will ultimately lead to a prosperous economy and increased living standards (Coleman, 2016). However, it is argued austerity impacts the most vulnerable groups in society the hardest (Horridge et al., 2018). 
In a recent article, Bulman (2018) reported that government austerity has manifested itself in budget cuts that have gone so deep they resulted in the bankruptcy of Northamptonshire council. A report by the Local Government Association (LGA) (2017) confirms this could be the first of many LAs to fail as a reduction in government grants will mean almost half all LAs will receive no central government funding by 2020. LAs were instead primed to retain more of their own business rates raised ( $75 \%$ raising to $100 \%$ instead of the current $50 \%$ ) (LGA, 2017). It is now Government policy that LAs are to have responsibility for their own funding decisions (Bulman, 2018). However, it is argued that this increase in business rates would not cover the funds lost from grants and will leave LAs facing a cliff edge in funding reduction as the business rate increase will not be in place during the phasing out of the current grant system (LGA, 2017). Therefore, by 2024 it is forecasted that majority of LA funding will come from council tax receipts and retained business rates and not from central government grants as is does currently (LGA, 2018).

LAs will therefore have to be self-sufficient, with money received equal or greater than money spent (presuming deficits will try to be avoided). This will potentially result in a more aggressive attitude to LA spending and further spending cuts. Whilst some may argue this may be a fairer system, a report from the Institute of Fiscal Studies found that those LA's who would receive the most from retained business rates would not necessarily be those LAs who had the most spending needs (Smith et al., 2018). The study models the impact of what the business rate reduction would have looked like between 2006 and 2014, finding 25\% of the LAs worst hit having $13 \%$ less spending power relative to their needs compared to the $25 \%$ of LA's who would have experienced the least cuts (Smith et al., 2018). Some LA's are therefore set to be worse off financially after the government strategy is fully implemented. However, it is argued that one-way LA's can seek to maximise expenditure, thereby offsetting some of the negative impacts of budget cuts, is by utilising the SVA during procurement (Cabinet Office, 2015).

\section{THE SOCIAL VALUE ACT (2012)}

The SVA places a legislative duty on public sector bodies in England and Wales to consider the wider value that can be achieved during procurement, and not just the lowest cost tender returned (Watson et al., 2016). Social value has been described as something that will add benefit to both immediate stakeholders and wider society (Kuratko et al, 2017). It is an actionable concept (Watson et al, 2016) that results in a positive contribution to communities 
(Raiden et al, 2019). At a more nuanced level, it is argued that only the social value created above and beyond the actual goods and services of the transaction can be considered as actual social value. However, there are currently no widely agreed metrics to measure the social value created through procurement, and the metrics that are used are subject to disagreement and confusion (Loosemore and Higgon, 2016). It is argued however, that such ambiguity is purposeful, as a Government review of the SVA reported that it allows LAs to identify and focus on the social value most important to them (Cabinet Office, 2015). Social value can therefore include practices that aim to have either short term or long-term benefits. However, it is an assumption made by all stakeholders that the social value practices undertaken ultimately result in some sort of benefit for the intended recipients. The SVA can therefore perhaps be considered as a positive tool in the arsenal of LAs in maximising spending, arguably helping achieve 'more for less' in their procurement (Watts et al, 2019).

However, whilst the use of SV is growing amongst LA's due to its legal requirement and the increased legitimacy it affords to LA's, it is argued the SVA is not widely utilised by all LAs due to low awareness, slow reactions in adopting new procurement strategies, a lack of leadership and a fear of legal challenges from its incorrect application (Cabinet Office, 2015). Where the SVA has been adopted benefits have been realised, with 'success stories' including an increase in fair trade products specified and more employment opportunities provided to disadvantaged groups (Loosemore and Higgon, 2016). Contractors, however, may argue that they have engaged in such behaviour long before the requirements of the SVA. Indeed, a review of contractor CSR reports revealed reports published in 2007 some 5 years before the introduction of the SVA, contain examples of contractors engaging in practices intending to improve society (Watts et al, 2019). It could therefore be argued that such socially responsible contractor behaviours were undertaken before the introduction of the SVA. It could be argued that the recent push towards SV forms part of the CSR movement and agenda which has been increasing and evolving since the 1950's.

\section{CORPORATE SOCIAL RESPONSIBILITY}

The modern advent of organisational CSR behaviour can be traced back to the publication of the book 'Social Responsibilities of the Businessman' by Bowen in 1953. Bowen argued for a giving back to society from business leaders due to the increasing industrial prosperity (Bowen, 1953). The concept has evolved since this time, focusing upon civil rights movements, woman's rights, consumer protection and environmental concerns as well as 
important social issues (Carroll, 2015). This evolution and increasing demand placed on organisations can be attributed to each generation expecting more responsibility from business in general. Such holistic expectations have made the concept of CSR diverse. CSR can therefore be described as organisations protecting and improving the welfare of the environment and wider society as part of their business activities (Carroll, 2015). Although like the concept of SV, CSR is ambiguous and means different things to different people (Barthorpe, 2010).

Requests from clients during procurement for additional metrics to be met, such as those considered as part of an organisations CSR, have also grown in importance. Now the criteria of time, cost and quality is no longer considered a triumvirate, and contractors are required to engage with and evidence their CSR in order to be successful during procurement. The benefits such CSR activity brings to stakeholders and intended recipients are also widely reported (Cabinet Office, 2015). Therefore, setting aside organisational motivations for CSR, it can be argued that the impacts of CSR activity are positive on both the environment and wider society. Indeed, it has been shown that one of the reasons contractors engage in CSR is for the positive difference it makes (Barthorpe, 2010). Arguably, the SVA has been introduced to harness the benefits offered by CSR and encourage more private sector organisations to adopt CSR practices. Therefore, some may believe that if the SVA was widely adopted by all LAs in all geographical regions, such CSR benefits would become more common and could alleviate negative issues experienced in society at the same time as alleviating some of the constraints LAs face due to funding cuts. It is with such thinking in mind that the widespread use of the SVA is encouraged (Cabinet Office, 2015). However, the relationship between the SVA and societal inequality is yet to be explored in the literature nor has any potential undesirable consequences of the SVA. This research seeks to offer one of the first explorations of the unintended negative impacts of the SVA and adopts the theoretical lens of legitimacy theory to assist in understanding key actor decisions.

\section{LEGITIMACY THEORY}

Legitimacy can be described as the perception that an organisation conforms to social norms and expectations and therefore has a social licence to operate (Bachmann and Ingenhoff, 2016). Legitimacy theory provides a theoretical framework to understand and explain how the decisions of individuals and organisations are governed and motivated by legitimacy 
seeking behaviours (Duff, 2017). It is argued there are 3 main categories of legitimacy, each with nuanced sub-categories as can be seen in table 1 .

\section{Type of Legitimacy}

\begin{abstract}
Pragmatic - Where practical and logic consequences arise from organisational exchanges with stakeholders
\end{abstract}

\section{Moral - Where stakeholders believe an organisation is doing the 'right thing'}

Cognitive - Where stakeholders believe an organisations motivation reflects their own

\section{Sub-Category}

Exchange - Organisations embrace practices they hope will result in legitimacy Influence - Stakeholders believe organisations consider societal interests Dispositional - Stakeholders believe organisations have societal concern Consequential - Stakeholders judge organisations on what they achieve

Procedural - Organisations adopt socially accepted practices

Structural - Stakeholders perceive an organisation is structured to achieve its advertised aims

Personal - Stakeholders believe those in charge of the organisation have high morals Comprehensibility - Where an organisation purposefully structures itself to be understandable to stakeholders

Taken for granted - Stakeholders perceive the organisation to be one of the only ones who can meet their needs

\section{Table 1. Legitimacy Classifications as derived from Duff (2017)}

Both individuals and organisations seek different types of legitimacy at different stages through their actions and communications and can attempt to progress along a continuum from pragmatic to cognitive legitimacy in the eyes of others (Belal and Owen, 2015). Legitimacy theory explains organisational decisions as being motivated by seeking legitimacy from stakeholders (Duff, 2017). Indeed, it could be argued that contractors embrace CSR to increase legitimacy perceptions amongst LA's which is achieved when LA's in turn procure only contractors who embrace CSR. This study adopts legitimacy theory as a lens to analyse and understand LA and contractor behaviour in regard to their adoption, encouragement and use of the SVA and wider CSR practices.

\section{RESEARCH METHOD}

In this research the view is adopted that social value is fundamentally a subjective concept as numerous arguments throughout the literature highlight how different stakeholders have different social value interpretations (Watts et al., 2018) This view therefore dictates a constructivist ontological position, with the understanding that meanings are socially constructed between different actors and are therefore best understood through a qualitative research strategy (Bryman, 2016). 
This research is concerned with the interpretation, enactment and ramifications of the SVA by both LAs and construction contractors, and so purposive sampling was undertaken. This is where participants are identified based on their ability to satisfy the research requirements (Robson and McCartan, 2017). In this research, the top 50 construction contractors by turnover were identified and ten picked at random. An online search for LA's who had an advertised use of the SVA was also undertaken, and from the twenty-two identified ten were picked at random. From the respective organisation websites, key actors who have responsibility for procurement of construction works, and those who have responsibility for carrying out SV practices, were selected. Email introductions were then sent to each individual outlining the research and requesting interviews. Six LAs and five contractors replied positively. In total eleven interviews were conducted. Galvin (2015) conducts an extensive review of 54 previous studies and concludes that in order for a researcher to have a high confidence in their findings 11-15 interviews are optimum. Semi-structured interviews were then conducted which allowed the core topics of interest to the research to be covered whilst allowing flexibility for the interviews to pursue interesting and unexpected lines of enquiry (Bryman, 2016). The interviews were conducted by telephone due to the wide geographical spread of the participants whilst also allowing the participants to respond to questions from comfortable and familiar surroundings (Creswell, 2013).

Narrative analysis was employed to encourage participants to discuss relevant topics and also as a method of analysing responses. Narrative analysis encourages interviewees to respond to questions asked by telling stories of their experience, with the researcher then extracting relevant information from these stories (Sandelowski, 1991). Such stories and responses are summarised and grouped together so detailed insights and understandings can be revealed (Loosemore and Bridgeman, 2018). In this research as participant understandings of the SVA were sought, in addition to examples of the SVA use, participants were requested to tell stories of how they have used or experienced the SVA, why it was used in those ways, in what contexts, and any benefits and drawbacks experienced. Any wider reflection shown by the interviewees when using the SVA, and potential consideration of ramifications, both positive and negative, were also discussed. The categories of legitimacy theory were used to both structure the interview questions and as themes by which to categorise responses. For example, LAs were asked if they judge contractors on their social value achievements (consequential legitimacy), and contractors were asked why they engaged with social value 
practices, and if they engaged with such practices to be viewed as legitimate (exchange legitimacy). Contractors were also asked the amount of LA work undertaken, their motivation for conducting SV practices, and if such SV practices were undertaken across all projects regardless of client. The LA's were also asked about the changes to their funding, procurement practices, and their previous and current social value requirements from contractors. The types of legitimacy then became headings under which the summarised responses gained through the narrative analysis were grouped. Any stories that shared characteristics with legitimacy theory categories were then grouped together under the appropriate heading. Thereby revealing if any aims or actions by either LA's or contractors were driven by legitimacy motivations, and if so, which type of legitimacy. This allowed a deeper consideration of stakeholder actions to be undertaken and allowed the theoretical lens of legitimacy to reveal deeper insights into stakeholder action and intention.

\section{FINDINGS AND DISCUSSION}

\section{Salient Findings}

Changes to LA funding is influencing
construction procurement decisions

The SVA is increasingly used, and does help LAs achieve more from procurement
LAs without the funds to use for construction projects may lose out on experiencing any SV related benefits within the areas they cover

Construction contractors engage with CSR and SV activity for the wider societal good and not simply to win work

\section{Relationship with Literature}

This builds on findings by Bulman (2018) and LGA (2018) that LA funding is changing with the potential ramifications for the construction industry illustrated. The paper provides the insight that LAs are aware of, and preparing for, changes to their funding by maximising use of the SVA.

The findings reinforce those in the literature of Raiden et al., (2019) and illustrate that recommendations made by the Cabinet Office (2015) are occurring in industry. Building on the use of legitimacy theory as a theoretical lens to understand behaviour (Duff, 2017), this paper contributes to understanding how legitimacy theory can govern client actions and this can influence contractor behaviour. Such findings build on existing research by LGA (2018) and Smith et al., (2018) and extend current findings to reveal possible negative connotations to current and planned Government policy.

Research by Watson et al., (2016) and Raiden et al., (2019) explore CSR and SV activity and these findings contribute to, reinforce and further our understandings of contractor CSR and SV motivations. 
The interviews with LA's revealed that changes to their funding are indeed underway, and are influencing procurement decisions, including impacting the way they procure construction contracts, confirming arguments in the literature. All LA's reported it was the introduction of the SVA that encouraged them to consider the wider benefits they could achieve from expenditure. All LA's also reported that prior to the introduction of the SVA, simply considering the lowest priced tender was acceptable and regularly undertaken. Although, the majority of the LA's revealed cost is still the most important factor, they reported the SVA now enables them to make further requests from each contractor. The interviews also reinforced arguments in the literature that LA's are attempting to ensure SV resulting from procurement occurs within their own geographical remit. This was to illustrate spending on issues of local importance to satisfy the majority of their stakeholders. All LA's were largely unapologetic about this and discussed how it was for the long term good of their own area. One LA even stated how they want local spend to occur within ten miles from the city centre and not ten miles from the location of the site, as sometimes the latter will cross the boundary of another LA and they want to retain all the spend benefits themselves.

The interviews also revealed that LAs acted this way in their search for moral and cognitive legitimacy in the eyes of local stakeholders such as community groups, residents and local business leaders. This raises the prospect of those LA's with lower socio-economic communities failing to raise enough funds to invest in construction projects and so therefore unable to experience the advantages the SVA offers. LA's who have the financial means, can therefore maximise the benefits their local communities experience. However, analysis of the interviews reveals that being motivated to achieve legitimacy in the eyes of immediate stakeholders, comes at the expense of wider stakeholders, with those LA's interviewed inadvertently serving to widen the wealth gap between affluent and poorer communities. When this was raised, LA's cited concerns about their own communities. Although no client wanted inequality to increase elsewhere, they all discussed how their responsibility was to their own populations first and foremost. Interestingly, the contractors did not acknowledge how the focus of their SV activities could perhaps contribute to wealth inequality and instead, like LA's, argued that such SV need would be picked up by LA's and contractors in those areas.

It was perhaps unsurprising to learn contractors discussed the procurement benefits CSR activity brings to their organisation. However, all those interviewed also strongly believed the 
benefits to society and the environment are the main motivations behind their CSR strategies and actions. Contractors generally believed they would still conduct SV practices even without the requirements imposed by the SVA and discussed current examples of CSR activity they were undertaking where the SVA had not been used, including for private sector clients who were not overly concerned with SV during procurement. Contractors also often structured their organisations with specially hired staff to oversee the social value practices undertaken (structural legitimacy) and perceive they had to adhere to LA expected practices expected (procedural legitimacy). It was also interesting that every contractor interviewed felt authentic support from top level management and business owners to deliver high impact social value practices (personal legitimacy). The use of legitimacy theory also revealed contractors were either motivated by, or at least aware of, the moral legitimacy benefits achieved by embracing CSR activity. Contractors are therefore willing to conduct CSR activity in the locations specified by LA's if it meant they could be both successful in procurement and engage with CSR activity.

\section{CONCLUSION}

This research offers one of the first explorations of the unintended negative impacts of the SVA and the potential scenarios that could arise if the SVA is increasingly adopted by LAs. This increasing use is both encouraged by central government, and somewhat driven by the government's austerity measures and the upcoming changes to how LAs receive funding resulting in future budget cuts. The research findings reveal that whilst contractors are motivated to embrace CSR for the benefit of society, current legislative and procurement practices dictate the focus of such CSR. If this focus is within a LA's geographical remit, the contractor will ultimately be more successful in public sector procurement. The most affluent LA's will procure construction works and receive SVA benefits, further enhancing their communities and so increasing the funds they receive to invest in construction work. Whereas LA's without enough funds to invest will not experience the same SV benefits from contractor CSR activity. The focus of such CSR activities solely in areas at the discretion of affluent LA's utilising the SVA could inadvertently contribute to increasing social inequality.

The limitations of this study include the number of interviewees conducted, as they cannot be said to be representative of the hundreds of LA's and contractors operating in the UK. Therefore, the generalisability of the research findings are limited. It would also be of interest to compare the actions of LA's who have elected mayors and those who do not, to reveal if 
the shifting focus of local politics impacts how LA's spend their budgets. It is recommended that further research will need to be conducted with a wider sample of LAs. Including those of different socio-economic levels, and those who do and do not use the SVA in procurement of construction works to increase understanding of the wider SVA ramifications. This research is of particular importance to contractors tendering for LA work and for those contractors motivated to engage in CSR by a desire to positively contribute to society. The research is also of importance to LA's and Government policy makers in their consideration of the successes and failures of the SVA. The findings of this research add to the current understanding surrounding SV procurement in the UK construction industry and highlight previously unexplored areas of importance regarding the use of the SVA. It is therefore recommended that LAs think carefully before they use the SVA and perhaps a longer term, nationwide approach to harnessing the power of contractor CSR should be discussed amongst all LAs to ensure the benefits can be experienced by all geographical regions.

\section{REFERENCES}

Barthorpe, S. (2010). Implementing corporate social responsibility in the UK construction industry. Property Management, 28(1), p.4-17.

Bachmann, P. and Ingenhoff, D. (2016). "Legitimacy through CSR disclosures? The advantage outweighs the disadvantages", Public Relations Review. Vol. 42, pp 386-394 Belal, A. and Owen, D. (2015). The rise and fall of stand-alone social reporting in a multinational subsidiary in Bangladesh. Accounting Auditing and Accountability Journal 27(8)

Bowen, H. (1953). Social Responsibilities of the businessman. New York: Harper \& Row. Bryman, A (2016) Social Research Methods. 5th Ed. Oxford. Oxford University Press. Bulman, M. (2018). English councils brace for biggest government cuts since 2010 despite 'unprecedented' budget pressures. The Independent. Published Monday 1 Oct 2018. Cabinet Office (2015). Social Value Act Review. February 2015. London.

Carroll, A. (2015), Corporate Social Responsibility: The centrepiece of competing and complementary frameworks. Organisational Dynamics. 44, p.87-96.

Coleman, R. (2016). Austerity futures: Debt, temporality and (hopeful) pessimism as an austerity mood. New Formations, 87, 83-101.

Creswell, J. (2013), Qualitative Inquiry and Research Design: Choosing Among Five Approaches. London. Sage Publications. 
Duff, A. (2017). Corporate social responsibility as a legitimacy maintenance strategy in the professional accountancy firm. The British Accounting Review. 49(6), p.1-19

Galvin, R. 2015. How many interviews are enough? Do interviews in energy consumption research produce reliable knowledge? Journal of Building Engineering 1. p.2-12

Horridge, K., Dew, R., Chatelin, A., Seal, A., Macias, L., Cioni, G., Kachmar, O., and Wilkes, S. (2018) Austerity and Families with Disabled Children: A European Survey. Developmental Medicine \& Child Neurology.

Kuratko, D., McMullen, J, and, Hornsby, C (2017). Is your organisation conducive to the continuous creation of social value? Toward a social corporate entrepreneurship scale. Business Horizons. 60, p271-283.

Local Government Association. (2017). Council funding to be further cut in half over next two years. London.

Local Government Association. (2018). Local Government Funding. Moving the Conversation On. London.

Loosemore, M, and Bridgeman, J. (2017). Corporate Volunteering in the construction industry: costs and benefits. Construction Management and Economics. Vol 35 (10). Loosemore, M. and Higgon D. (2016) Social Enterprise in the Construction Industry. Routledge, Oxon. Cabinet Office, 2015)

Raiden, A., Loosemore, M., King, A and Gorse, C (2019). Social Value in Construction. Routledge, Oxon.

Rhodes, C. (2019). Construction Industry: statistics and policy. Nr 01432. House of Commons Library. www.parliament.uk/briefing-papers/sn01432.pdf.

Robson, C, and, McCartan, K. (2017). Real World Research. 4th Edition. John Wiley and Sons. London.

Sandelowski, M. (1991). Telling stories: Narrative Approaches in Qualitative Research. The Journal of Nursing Scholarship. 23(3), p161-166.

Smith, N., Phillips, D, and Simpson, P (2018). 100\% business rates retention may lead to divergences in English councils' funding without growth. Institute for Fiscal Studies.

Watson, K. J., Evans, J., Karvonen, A., and Whitley, T. (2016). Capturing the social value of buildings: The promise of Social Return on Investment (SROI). Building and Environment, 103, p289-301.

Watts, G., Dainty, A. and Fernie, S. (2019). Paradox and Legitimacy in Construction: how CSR Reports Restrict CSR Practice. International Journal or Building Pathology and Adaptation. 37(2), p231-246. 